Journal of Archaeological Science 39 (2012) 3683 - 3690

http://dx.doi.org/10.1016/j.jas.2012.06.007

\title{
Optical coherence tomography for the non-invasive investigation of the microstructure of ancient Egyptian faience
}

Haida Liang ${ }^{\mathrm{a}}$, Margaret Sax ${ }^{\mathrm{b}}$, David Saunders ${ }^{\mathrm{b}}$, Mike Tite ${ }^{\mathrm{c}}$

\author{
${ }^{a}$ School of Science and Technology, Nottingham Trent University, Nottingham \\ NG11 8NS, UK \\ ${ }^{b}$ Department of Conservation and Scientific Research, The British Museum, London \\ WC1B 3DG, UK \\ ${ }^{c}$ Research Laboratory for Archaeology and the History of Art, Oxford OX1 3QY, UK
}

Corresponding author: Haida Liang, email: Haida.Liang@ntu.ac.uk

\begin{abstract}
Optical Coherence Tomography (OCT) is a non-invasive subsurface 3D imaging technique based on the Michelson interferometer. The non-invasive nature of OCT and its speed of acquisition makes it possible to image large volumes of intact objects to yield a complete overview of the microstructure. The production methods for ancient Egyptian faience were first investigated using scanning electron microscopy (SEM) imaging of the microstructure in polished sections and microprobe analysis of the composition of the glass phases. These studies were based on original Egyptian faience objects and laboratory reproductions of faience beads made using three different production methods. The microstructure of the same laboratory samples and the Egyptian faience objects from the British Museum Research Laboratory Collection are re-examined using OCT. It is found that OCT virtual cross-section images can be used to group ancient faience objects into three categories on the basis of the morphology of the surface glaze layer and the glaze-core interaction layer. The OCT images correspond well with SEM images of polished sections of ancient faience objects and laboratory reproductions. The virtual cross-sections produced by OCT are somewhat limited by the penetration depth, which is affected by the high absorption coefficient of the material and, therefore, cannot always provide information on the presence or absence of interparticle glass that binds together the quartz particles in the core. Nevertheless, the top two layers are well imaged and since OCT images can be obtained rapidly and without the necessity of removing a sample, the method can be applied to a very much wider range of ancient faience objects than is possible by SEM examination of polished crosssections. In summary, this paper examines to what extent OCT can assist the investigation of the production techniques of ancient Egyptian faience.
\end{abstract}

Keywords: Egyptian faience, optical coherence tomography, non-invasive imaging, microstructure, SEM, glaze

\section{INTRODUCTION}

Ancient Egyptian faience consists of a quartz sand or ground quartz body, bonded together by varying amounts of glass phase and coated with an alkali-lime glaze which is typically coloured turquoise blue by the addition of a copper colorant. The manufacture of faience in Egypt dates back to the fourth millennium BC (Nicholson and Peltenburg, 2000 and references therein). Three methods for the production of ancient Egyptian faience have been identified (Tite et al. 2008): (i) application glazing in which a slurry is prepared either directly from a mixture of quartz, alkali flux, calcium carbonate and colorant (or from a ground, pre-fritted mixture of the same components) and applied to the quartz body prior to drying and firing to about $950^{\circ} \mathrm{C}$; 
(ii) efflorescence glazing in which the glazing components are mixed with the quartz. Water is added, and objects are formed from the resulting paste. During subsequent drying, the soluble salts migrate to the surface to form a thin layer from which the glaze is produced after firing; and (iii) cementation glazing (Qom technique) in which the quartz bodies are buried in the glazing mixture and fired to about $1000^{\circ} \mathrm{C}$. After firing, the glazing mixture is broken away from the faience objects that are now coated with glaze.

The microstructures of Egyptian faience and beads prepared in the laboratory using the aforementioned three methods of production were studied and compared in detail by Tite et al. (1983), Tite \& Bimson (1986) and Tite et al. (2007) using SEM (scanning electron microscope) images of polished sections. The results showed that faience microstructures typically consist of (I) an outermost, essentially quartz-free glaze layer; (II) a glaze/core interaction layer consisting of quartz embedded in a more-or-less continuous matrix of glass; and (III) the core itself containing varying amounts of interparticle glass binding together adjacent quartz particles (Figure 1). Tite and Bimson (1986) also proposed that the different glazing methods could be distinguished on the basis of differences in the glaze and interaction layer thicknesses, and in particular, that efflorescence glazing could be distinguished from cementation and application glazing by the presence or absence, respectively, of interparticle glass in the core.

\section{Place Figure 1 here}

\section{OPTICAL COHERENCE TOMOGRAPHY IMAGING OF FAIENCE}

Optical Coherence Tomography (OCT) is a fast imaging Michelson interferometer capable of non-invasive and non-contact imaging of the 3D subsurface microstructure of transparent or semi-transparent material. OCT was first invented for the in vivo 3D imaging of the eye including the retina (Huang et al. 1991). More recently, it has been applied to the non-invasive imaging of paint and varnish layers of paintings (e.g. Liang et al. 2005, Targowski et al. 2004) and painted objects, jades, ceramics, glass and other archaeological objects (Liang et al., 2008, Targowski and Iwanicka, 2011 and references therein). OCT was found to be particularly useful in imaging vitreous objects such as ancient glass (Liang et al. 2007, 2008, Sywestrzak et al. 2009, Kunicki-Goldfinger et al. 2009, Iwanicka et al. 2011), ceramic glaze (Liang et al. 2008, Targowski et al. 2011, Yang et al. 2009) and painted enamel (Liang et al. 2008).

The OCT used in the current study is a Thorlabs SROCT operating at $930 \mathrm{~nm}$. It has a depth resolution of $6.5 \mu \mathrm{m}$ in air (or $\sim 4.5 \mu \mathrm{m}$ in faience) and a transverse resolution of $\sim 9 \mu \mathrm{m}$. There are in general two classes of OCT: time-domain and Fourier domain. In a time-domain OCT, interference fringes formed between the light reflected from the reference mirror and the sample are generated in a time sequence by scanning the reference mirror in order to vary the reference path length. Maximum signal is obtained when the reference path length matches that of the light scattered back from the sample. Scattering intensity from the sample is greatest at refractive index discontinuities such as the air/faience boundary. In a Fourier domain OCT such as the Thorlabs SROCT used in the current study, the reference mirror is fixed and the 
interference fringe is obtained by dispersing the interference signal through a diffraction grating and collecting it with a linear array detector. This spectrum is then post-processed and Fourier transformed to obtain the depth profile. A typical virtual cross-section image of a piece of faience is shown in Fig. 3d where the top bright (white) curve is the air/glaze boundary, the thin dark layer is a uniform transparent glaze layer and the thicker diffuse white layer is a highly scattering layer consisting of material with inhomogeneous refractive indices such as a mixture of glaze and quartz grains in the glaze/core interaction layer.

Since OCT measures optical path length rather than physical thickness, we will assume a refractive index of 1.45 for the glaze and quartz in the rest of the paper. Refractive indices of glaze are likely to be similar to glass which usually range between 1.4 and 1.55. Physical thickness is equal to the optical thickness divided by the refractive index. All thickness measurements will be given in physical thickness unless otherwise specified.

\section{COMPARISON OF OCT AND SEM IMAGES}

In this section, OCT images of faience are compared with SEM images of polished sections from the same object. An $18^{\text {th }}$ Dynasty Egyptian faience ring (BMRL16321) (Fig 2a) is used to illustrate how an OCT virtual cross-section image can be interpreted. The SEM image of a polished section (Fig. 2b) shows that it has a welldefined uniform quartz-free glaze layer of $\sim 60 \mu \mathrm{m}$ (layer I) followed by a glaze/core interaction layer of $\sim 350 \mu \mathrm{m}$ (layer II). Small areas of interparticle glaze (white) binding together adjacent quartz particles are visible in the core (layer III), the grain size of these particles being $<50 \mu \mathrm{m}$ (Table 1, Tite et al. 1983). The glaze regions are white, the grey regions are quartz and the black regions are voids. In comparison, the OCT images of virtual cross-sections across the decorated surface of the ring (Fig. 2c) show a transparent layer of glaze with a thickness between $<4.5$ and $>200 \mu \mathrm{m}$. The OCT images across the back of the ring (Fig. 2d) indicate a glaze layer with a thickness that falls into the same range. The glaze/core interaction layer appears to have a thickness of $\sim 80-210 \mu \mathrm{m}$. It is important to note that any multiple scattering will overestimate the thickness because OCT is only sensitive to the optical path length. On the other hand, strong absorption will underestimate the thickness. These thickness ranges are obtained from images over 6 by $4 \mathrm{~mm}$ or 10 by $4 \mathrm{~mm}$ transverse areas, i.e. hundreds of virtual cross-sections. The maximum OCT depth range is always $1.6 \mathrm{~mm}$ in air (or $\sim 1.1 \mathrm{~mm}$ in faience). In comparison, the SEM image in Fig. $3 \mathrm{~b}$ has only sampled one cross-section, although the microstructures shown in the figure are representative of those observed in the overall sampled area, which is several millimetres across. The thickness of the glaze measured from the OCT images are consistent with the SEM image. In addition, Fig.2c shows some weathering features in the glaze layer (multiple bright interfaces within the dark glaze layer). These weathering features show the delamination of glaze layers similar to those of gel layers on weathered ancient Egyptian glass (Liang et al. 2008). Figure 2d shows an image artefact, a faint line below the bright air/glaze interface which is twice the distance from the top of the image as the top bright interface is from the top, due to the non-linearity of the detector near saturation. Such image artefacts are commonly associated with bright interfaces. 


\section{Place Figure 2 Here}

However, it is clear that the signal is greatly attenuated in the OCT images beyond a layer II thickness of $\sim 210 \mu \mathrm{m}$. The OCT cannot see through layer II to the core regions. To find out what the core region would look like in an OCT virtual crosssection image, OCT images (Fig. 2f) were taken across the broken cross-section of the ring, exposing the core region as shown in Fig. $2 \mathrm{e}$. Figure $2 \mathrm{f}$ shows that the core region (layer III) scatters light much more strongly than the glaze/core interaction region (layer II) because the quartz particles in the core region are surrounded by air rather than glaze and the refractive index difference between quartz and glaze is tiny compared with that between quartz and air. Layer III is clearly not seen in the OCT images across the front and back of the ring (Fig. 2c,d) due to attenuation of the light by layers I and II. In addition, Fig. 2f shows that layer II can be as thick as $700 \mu \mathrm{m}$, as shown by the less highly scattering regions to the left and right of the central core. This example demonstrates that OCT can clearly see layer I and upper parts of layer II, but cannot see through to layer III. One of the limitations of spectrometer-based Fourier domain OCT is a decrease in sensitivity as a function of probing depth, in addition to the depth of field limitation. The depth-of-field is inversely proportional to the numerical aperture of the objective lens and the decrease in sensitivity with depth is determined by the spectral resolution of the spectrometer (Hausler and Lindner 1998). A time-domain OCT operating at $800 \mathrm{~nm}$, with auto-focusing capability to reduce the depth-of-field effect, was used to probe the same object in the hope of achieving a greater depth of penetration. However, it was still not able to see layer III (Hughes 2010).

\section{Place Figure 3 Here}

The SEM image (Fig. 3b) of the New Kingdom ring (BMRL 16319) shows that it has pockets of glaze of $20-100 \mu \mathrm{m}$ in thickness and a glaze/core interaction layer that is $\sim 250 \mu \mathrm{m}$ thick. Small areas of interparticle glaze (white) binding together adjacent quartz particles $(<80 \mu \mathrm{m}$ in grain diameter) are again visible in the core. An OCT image of the microstructure shows that it has a well-defined glaze layer of $\sim 40-70 \mu \mathrm{m}$ and a glaze/core interaction layer of thickness $\sim 160-210 \mu \mathrm{m}$ (Fig. 3c). The core region is not visible in the OCT image, possibly due to absorption by the layers above. Figure $3 \mathrm{c}$ shows weathering features in the glaze layer where the presence of multiple bright interfaces suggest the start of the delamination process.

However, no uniform glaze layer was detected in the OCT image of another region shown in Fig.3d. This shows that the glaze layer is not uniform over the whole object. It also high lights one of the advantages of using a non-invasive technique like the OCT where it is possible to map large areas of an object and therefore having a more representative view of the microstructure than that provided by an invasive technique like the SEM. On the other hand, SEM should be seen as complementary to the OCT for providing microstructure images of the core which cannot be seen by the OCT. 
The OCT and SEM images are overall consistent with each other and both are similar to the earlier images shown in Fig. 2 .

\section{Place Figure 4 here}

The SEM image (Fig. 4b) of the $21^{\text {st }}$ Dynasty Egyptian shabti (BMRL 16323) showed that the glaze layer was $20-100 \mu \mathrm{m}$ thick and the glaze/core interaction layer was $\sim 200 \mu \mathrm{m}$. In this case, no interparticle glass binding together the quartz particles was visible in the core. In addition, the quartz particles $(<\sim 50-200 \mu \mathrm{m}$ in size $)$ in this object appear to be larger than those in the ring. The OCT images in Fig. 4c,d show that the glaze layer thickness varies significantly from $<4.5$ to $>150 \mu \mathrm{m}$ and that the glaze/core interaction layer varies in thickness from $\sim 200$ to $350 \mu \mathrm{m}$. The highly scattering region with a well-defined boundary seen in Fig. $4 \mathrm{~d}$ is likely to be associated with the core region. Figure $4 \mathrm{~d}$ also shows that the surface of the glaze, just above the region where the core is seen, has lost its top layer possibly due to weathering.

\section{Place Figure 5 here}

The SEM image (Fig. 5b) of the Late Period shabti figure (BMRL16322) shows that there are small high atomic number particles (white) embedded in a glaze of thickness $200-800 \mu \mathrm{m}$. Although these particles have not been identified, in view of the much higher bulk alumina content (determined by microprobe analysis) of the glaze for this object compared to the other glazes, they are probably calcium alumino-silicates. No glaze/core interaction layer was found. Again, the quartz particles in the core are 50$150 \mu \mathrm{m}$ in size and there is no interparticle glass binding them together. The OCT virtual cross-section image looks very different from any of the faience objects studied above. Instead of a clear glaze layer, it has a thick uniform scattering layer $\sim 230-330 \mu \mathrm{m}$ thick that has a few air bubbles (maximum diameter $170 \mu \mathrm{m}$ ) imbedded. The scattering appears to be due to very small particles imbedded in the glaze, probably the high atomic number particles observed in the SEM image, which might result from the different glaze composition compared with the other faience objects.

\section{Place Figure 6 here}

There is no available SEM image for the $21^{\text {st }}$ Dynasty Egyptian shabti, BMRL16324 (Fig 6a). The OCT image (Figs 6b) shows highly scattering regions down to a welldefined boundary which could be associated with the quartz core. The dark regions above this boundary are probably associated either with regions of uniform glaze or with pores within a glaze/core interaction layer. The OCT image reveals that the microstructure of this shabti is similar to the other $21^{\text {st }}$ Dynasty shabti (BMRL16323).

In summary, Fig. 4 and Fig. 6 show that the microstructures of the two shabtis, BMRL16323 and BMRL16324, as seen by OCT are very similar to each other but are different both from that for shabti, BMRL16322 (Fig. 5), and from those for the two 
rings, BMRL 16321 and BMRL16319, (Fig. 2 and 3). Thus, on the basis of the OCT virtual cross-section images, the ancient faience objects studied so far can be grouped into three categories: 1) the two rings both have a well-defined glaze layer; 2) the two $21^{\text {st }}$ Dynasty shabtis have pockets of glaze rather than a well-defined glaze layer; and $3)$ the Late Period shabti has a thick glaze layer with both small scattering particles and large air bubbles. In the first category, the OCT can see layers I and II; in the second category, the OCT can see all three layers in certain regions; and in the third category, the OCT can only see layer I.

Further, it is interesting to note that copper colorants such as malachite are often used in the glaze mixture (Tite et al. 2008), which also gives the turquoise colour of the faience. However, it is also known that the $\mathrm{Cu}^{2+}$ ions in the copper colorant have a strong broad absorption band near the current OCT operating wavelength of $930 \mathrm{~nm}$ (e.g. Peric 2008, Bae and Weinberg 1994). Microprobe analysis of the glass phase showed that the copper content of layers I and II for the rings are a factor of 2 to 3 greater than those of the shabtis (Tite et al. 1983), which may explain why it is possible to see through to the core in the cases of the two shabtis but not the rings.

On the basis of the microstructures observed in the SEM, the objects can be grouped into three similar categories, with the presence or absence of interparticle glass in the core providing an additional criterion. Thus, although one ring, BMRL 16321, has a well-defined, continuous glaze layer and the other, BMRL 16319, only pockets of glaze, interparticle glass is present in the cores of both rings. In contrast, although the $21^{\text {st }}$ Dynasty shabti, BMRL 16323, again has only pockets of glaze, interparticle glass is absent from the core. Thirdly, the Late Period shabti, BMRL 16322, has a very much thicker continuous glaze layer and again, no interparticle glass in the core. The ancient faience objects studied are consistently separated into the same 3 categories based on either SEM or OCT images.

\section{MICROSTRUCTURE AND PRODUCTION METHOD}

On the basis of the SEM microstructures observed for faience replicated in the laboratory using each of the glazing methods, that is, efflorescence, cementation and application, Tite et al. (1983) and Tite and Bimson (1986) proposed glazing methods for the ancient faience discussed above. Thus, principally because of the presence of interparticle glass in the core, they suggested efflorescence glazing for the two rings. Then, because of the irregular glaze layer and the absence of interparticle glass from the core, they suggested cementation glazing for the $21^{\text {st }}$ Dynasty shabti, BMRL 16323. The black decoration on the shabti could have been painted onto the shabti body before it was buried and fired in the glazing mixture. Finally, because of the very thick glaze layer and absence of interparticle glass in the core, they suggested direct application of a fritted glaze mixture for the Late Period shabti, BMRL 16322.

However, Tite and Bimson (1986) emphasised that the microstructural criteria suggested by the laboratory replications must be used with caution, and the need for caution was again strongly argued by Vandiver (1998). For example, for cementation glazing, depending both on the particle size of the quartz, and on the firing temperature and time, the glass phase can penetrate to depths of at least $1 \mathrm{~mm}$. Thus, for objects with thin cross-sections, such as the two rings, cementation glazing could 
produce a similar microstructure to that resulting from efflorescence glazing, with considerable interparticle glass bonding together the quartz particles throughout the core.

Further, with both cementation and application glazing, some glazing mixture could have been added to the quartz core in order to facilitate forming the object and to increase its strength both before and after firing. This would result in the formation of interparticle glass within the core, such that the microstructure might not differ significantly from that associated with efflorescence glazing. In conclusion, therefore, it is only the absence of interparticle glass in faience cores that provides an unambiguous criterion for distinguishing cementation and application glazing from efflorescence glazing.

In addition to the OCT examinations of ancient faience, as described above, OCT images have been obtained from the replicate faience beads prepared and examined in a SEM by Tite et al. (1983) and Tite and Bimson (1986). For the replicate beads glazed by the efflorescent method, the OCT images show very irregular thicknesses of clear glaze together with areas of scattering by quartz particles and/or pores in the glaze/core interaction layer (Fig. 7a and 7b). Increasing the firing temperature resulted in decreased scattering because of the expected increased dissolution of the quartz grains. In contrast, for beads glazed by the cementation method, the OCT images show somewhat more regular thin glaze layers and thicker scattering layers associated with the glaze/core interaction layer (Fig. 7c and 7d). For beads glazed by the direct application of a fritted glaze mixture, the OCT images show only limited scattering (Fig. 7e and 7f). Further, because of dissolution of the quartz and elimination of pores, the scattering decreases significantly as the firing temperature is increased from 850 to $980^{\circ} \mathrm{C}$ to show a thick surface glaze layer (Fig. 7e and 7f).

\section{Place figure 7 here}

As with the SEM microstructures, the methods of glazing used for the ancient faience can be tentatively inferred by comparing their OCT images with those for the replicate faience beads. Thus, on the basis of the uniform glaze layer exhibited by the rings (Fig. 2c, 2d, 3c and 3d), cementation would seem to be the more likely method of glazing (Fig. 7c and 7d), and in view of the small size of the rings, this is one of the options consistent with the observed SEM microstructure.

Because of the absence of a uniform glaze layer, the OCT images of the $21^{\text {st }}$ Dynasty shabtis (Fig. 4c, 4d, 6c and 6d) tend to be closest to those for the replicate faience glazed by the efflorescence method (Fig. $7 \mathrm{a}$ and $7 \mathrm{~b}$ ). However, the absence of any interparticle glass in the core of shabti BMRL 16323 (Fig. $4 \mathrm{~b}$ ), means that the efflorescence method could not have been used, at least, for this shabti.

On the basis of the presence of a single thick uniform scattering layer, the OCT image of the Late Period shabti (Fig. 5c) is closest to those of beads produced by the direct application method using a fritted glaze mixture (Fig. 7e and 7f). This interpretation is consistent with that based on the SEM microstructure. The difference in appearance between OCT images for the replicate bead and the shabti is likely to be due to the 
presence of small, high atomic number particles that have crystallised from the shabti glaze as a result of its high alumina content.

\section{CONCLUSIONS}

OCT is a non-invasive and non-contact imaging method that can provide images of layer structures over a large area and therefore offer a better representation of the overall microstructure than SEM images. Since images of the layer structure can be obtained without the necessity of removing a sample, the method can be applied to a very much wider range of ancient faience objects than would be possible by SEM examination of polished cross-sections. This fact, together with the ease of operation and speed of image acquisition of OCT, allows efficient imaging of substantial areas of a significant number of objects.

OCT can image the top glaze layer and a significant part of the glaze/core interaction layer, but cannot always penetrate faience objects deeply enough to see the quartz core itself (although in some regions it is possible to see the core). Therefore, in contrast to the SEM examination of polished cross-sections, OCT cannot always provide information on the presence or absence of interparticle glass binding together the quartz particles in the core, which is a crucial parameter for distinguishing cementation and direct application glazing from efflorescence glazing. However, in spite of this limited depth penetration, OCT images can be used to group ancient faience objects into three categories on the basis of the morphology of the top two layers, and for the ancient faience studied, this categorization was the same as that obtained on the basis of SEM microstructures.

Regarding the method of glazing used, its conclusive determination is difficult from either SEM microstructures or OCT images, and in any case, the choice of glazing method is frequently determined mainly by the type of faience object being produced. For example, cementation glazing has the advantage that a large number of small objects (less than about a centimetre across) can be glazed en masse without leaving drying or firing marks on their surfaces. However, it is less appropriate for bigger objects because of the large quantities of glazing mixture that would be required. Efflorescence glazing has the advantage that, in combination with moulding to shape, it provides an efficient method for the large scale production of objects up to some $20-30 \mathrm{~cm}$ across. Application glazing is particularly appropriate for objects such as inlays and large tiles that only need glazing on one side, and for polychrome objects.

However, in spite of these difficulties in determining the method of glazing, the microstructure of faience remains important in assessing both its production technology and its performance characteristics in use. In this context, because OCT images can be obtained rapidly and non-invasively, the method can be used to obtain microstructural information for large groups of ancient faience objects. Assistance in the interpretation of the microstructures of the categories, thus defined, can then be obtained by the SEM examination of polished cross-sections of samples taken from a very much smaller number of representative objects. 


\section{ACKNOWLEDGEMENTS}

Funding from the Leverhulme Trust and the AHRC/EPSRC Science and Heritage Programme are gratefully acknowledged. We would like to thank Stephan Röhrs (British Museum), Samuel Lawman (Nottingham Trent University), Borislava Peric (Nottingham Trent University) for help with the OCT imaging sessions at the British Museum and Antony Simpson (British Museum) for help with the drawings.

\section{REFERENCES}

Bae, B., Weinberg, M.C., 1994. Optical absorption of copper phosphate glasses in the visible spectrum. Journal of Non-Crystalline Solids, 168, 223-231.

Hausler, G., Lindner, M.W., 1998. "Coherence radar" and "Spectral radar" - new tools for dermatological diagnosis. Journal of Biomedical Optics, 3(1), 21-31.

Huang, D., Swanson, E. A., Lin, C. P., Schuman, J. S., Stinson, W. G., Chang, W., Hee, M. R., Flotte, T., Gregory, K., Puliafito, C. A., Fujimoto, J. G. 1991. Optical coherence tomography. Science, 254, 1178-1181.

Hughes, M., 2010. Optical coherence tomography for art, conservation and archaeology: methods and applications. $\mathrm{PhD}$ thesis, University of Kent in Canterbury, UK.

Iwanicka, M., Kwiatkowska, E. A., Sylwestrzak, M., Targowski, P., 2011.

Application of optical coherence tomography (OCT) for real time monitoring of consolidation of the paint layer in Hinterglasmalerei objects. Proc. SPIE 8084, $80840 \mathrm{G}$.

Kunicki-Goldfinger, J., Targowski, P., Góra, M., Karaszkiewicz, P., Dzierżanowski , P., 2009. Characterization of glass surface morphology by optical coherence tomography. Studies in Conservation 54, 117-128.

Liang, H., Cid, M., Cucu, R., Dobre, G., Podoleanu, A., Pedro, J., Saunders, D., 2005. En-face optical coherence tomography - a novel application of non-invasive imaging to art conservation. Optics Express, 6133-6144.

Liang, H., Peric, B., Hughes, M., Podoleanu, A., Spring, M., Saunders, D., 2007.

Optical coherence tomography for art conservation and archaeology. Proc. SPIE 6618, 661805 .

Liang, H., Peric, B., Hughes, M., Podoleanu, A., Spring, M., Roehrs, S., 2008. Optical coherence tomography in archaeological and conservation science - a new emerging field. Proc. SPIE, 7139, 713915.

Nicholson, P.T. and Peltenburg, E., 2000. Egyptian Faience, in: Nicholson, P.T. and Shaw, I. (eds.), Ancient Egyptian Materials and Technology, Cambridge: Cambridge University Press, pp.177-194. 
Peric, B., 2008. Optical coherence tomography applied to investigations of optical properties of paintings. MPhil thesis, Nottingham Trent University, UK

Sylwestrzak, M., Kwiatkowska, E. A., Karaszkiewicz, P., Iwanicka, M., Targowskia P. , 2009. Application of graphically oriented programming to imaging of structure deterioration of historic glass by Optical Coherence Tomography. Proc. SPIE 7391, 73910A.

Targowski, P., Rouba, B., Wojtkowski, M., Kowalczyk, A., 2004. Application of optical coherence tomography to non-destructive examination of museum objects. Studies in Conservation, 49, pp.107-114.

Targowski, P., Iwanicka, M., 2011. Optical coherence tomography for structural examination of cultural heritage objects and monitoring of restoration processes - a review. Applied Physics A, 106(2), Special Issue on "Optical Technologies in Art and Archaeology", pp.265-277.

Tite, M. S., Freestone, I. C., Bimson, M., 1983. Egyptian faience: an investigation of the methods of production. Archaeometry, 25 (1), 17-27.

Tite, M. S. and Bimson, M., 1986. Faience: an investigation of the microstructures associated with the different methods of glazing. Archaeometry, 28(1), 69-78.

Tite, M S, Manti, P, Shortland, A J, 2007. A technological study of ancient faience from Egypt. Journal of Archaeological Science, 34, 1568-1583.

Tite, M. S., Shortland, A. J., and Vandiver, P. B., 2008. Chapter 3 Raw materials and fabrication methods used in the production of faience, in: Tite, M.S. and Shortland, A.J. (eds.), Production technology of faience and related early vitreous materials, Oxford University School of Archaeology Monograph 72, Oxford, pp.37-55.

Vandiver, P. B., 1998. A review and proposal of new criteria for production technologies of Egyptian faience, in: Colinart S. and Menu M. (eds.), La couleur dans la peinture et l'émaillage de l'Égypte Ancienne, Edipuglia, Bari, 121-139.

Yang, M.-L., Winkler, A. M., Barton, J. K., Vandiver, P. B., 2009. Using optical coherence tomography to examine the subsurface morphology of chinese glazes, Archaeometry, 51, 808-821. 
Figures:

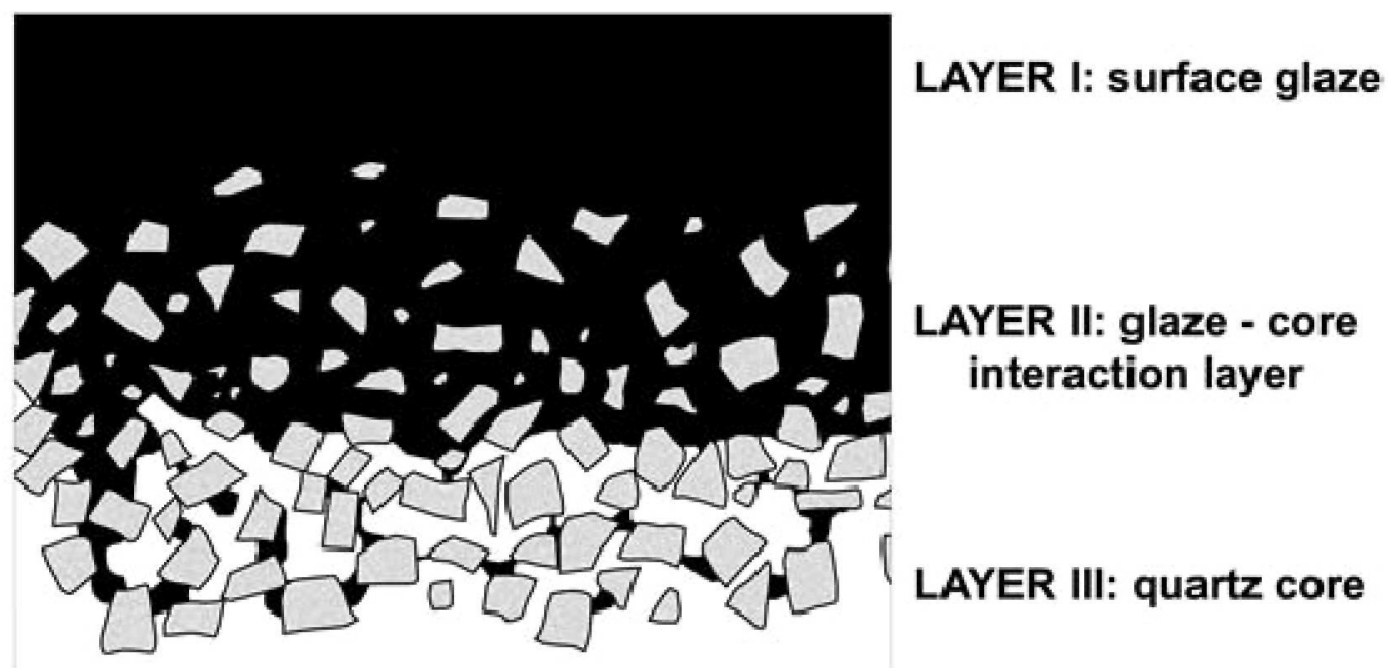

Figure 1. Schematic of the structure of faience after Tite and Bimson (1986). 


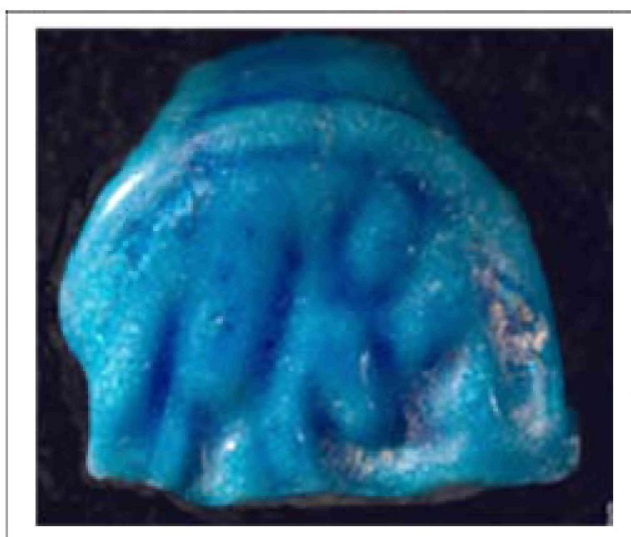

(a)

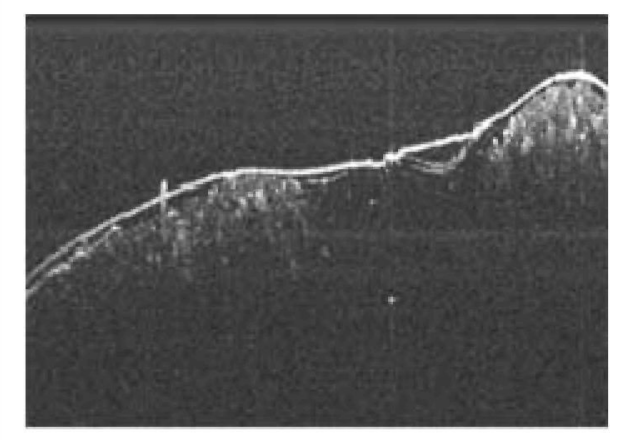

(c)

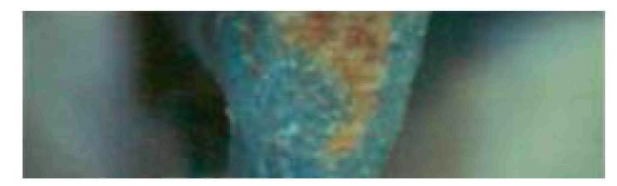

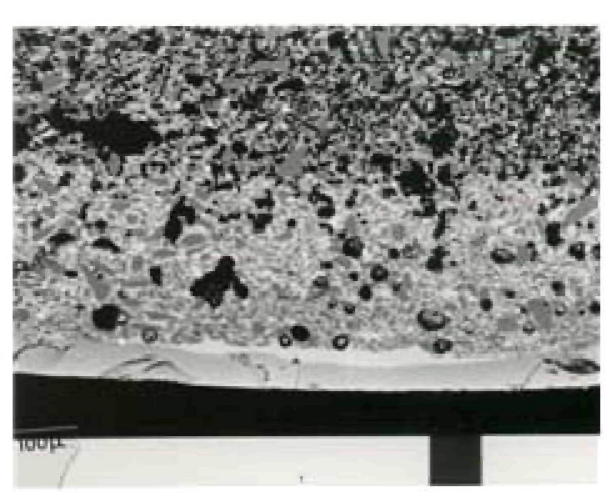

(b)

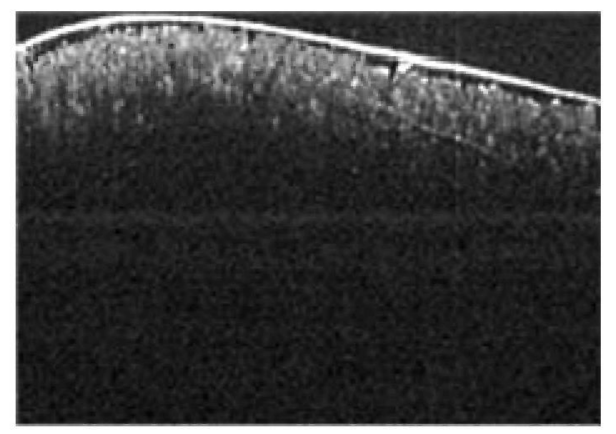

(d)

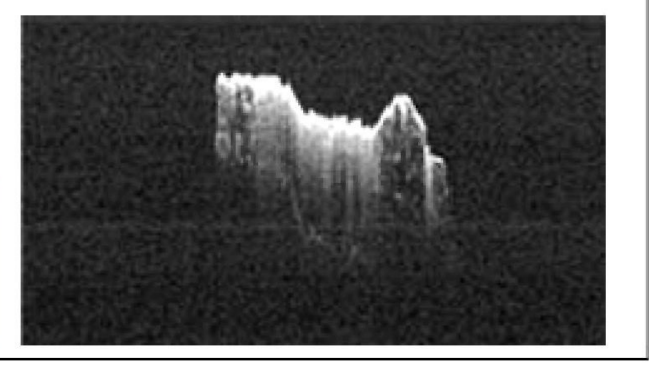

Figure 2. A fragmentary Egyptian $18^{\text {th }}$ Dynasty ring BMRL16321: a) colour image of the front of the ring; b) SEM image of a polished cross-section from Tite et al. (1983), where the glaze is represented in white (the outer glaze layer is weathered and slightly greyer than the inner layer), the quartz particles appear grey and the black regions are the voids. The black marker on the bottom left of the image shows a scale of $400 \mu \mathrm{m}$; c) OCT non-invasive virtual cross-section images of the front of the ring (video); d) OCT virtual cross-section image of the back of the ring; e) colour image of the exposed cross-section close to where the polished section was taken for SEM examination; f) OCT virtual cross-section image of the exposed cross-section taken across the red line in (e). The OCT images are of the same scale and the white scale bars on the bottom left in (c) show scales of $400 \mu \mathrm{m}$. 


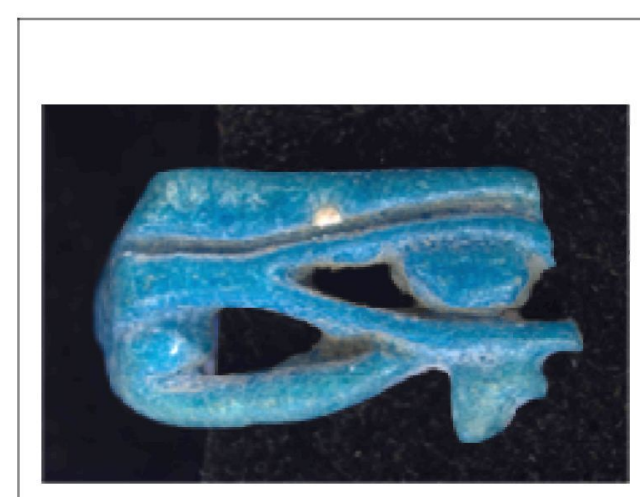

(a)

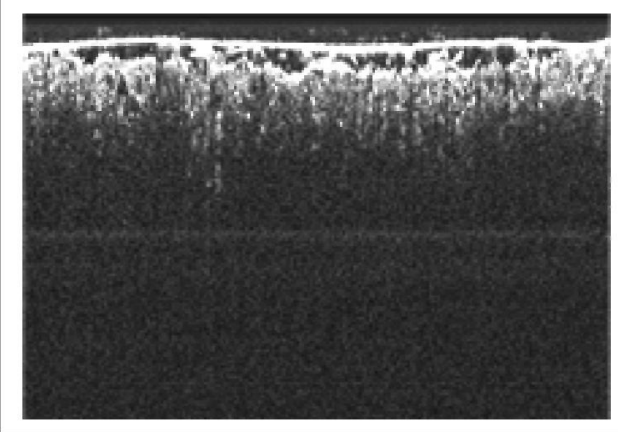

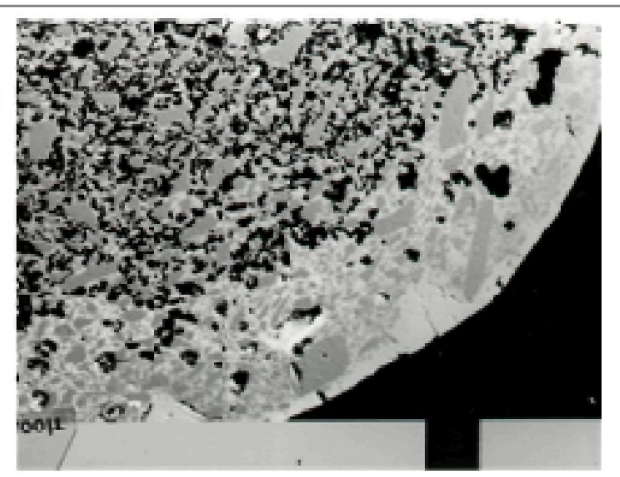

(b)

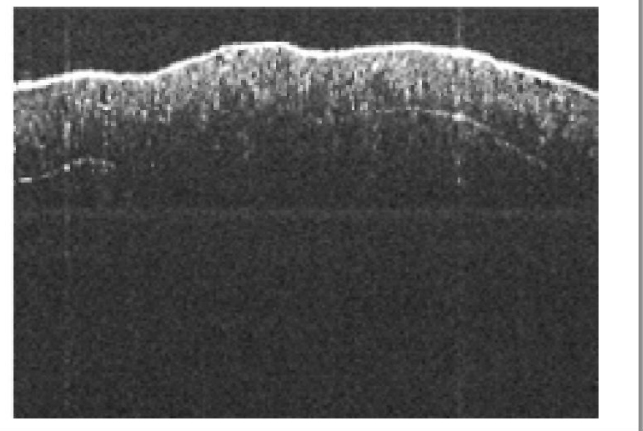

Figure 3: A fragmentary Egyptian New Kingdom ring (BMRL 16319): a) colour image of the image; b) SEM image of a polished cross-section, where the glaze is white, the quartz particles grey and the voids black. The black marker on the bottom left of the image shows a scale of $400 \mu \mathrm{m}$; c-d) OCT virtual cross-section images. The OCT images are of the same scale and the white scale bars on the bottom left in (c) show scales of $400 \mu \mathrm{m}$. 


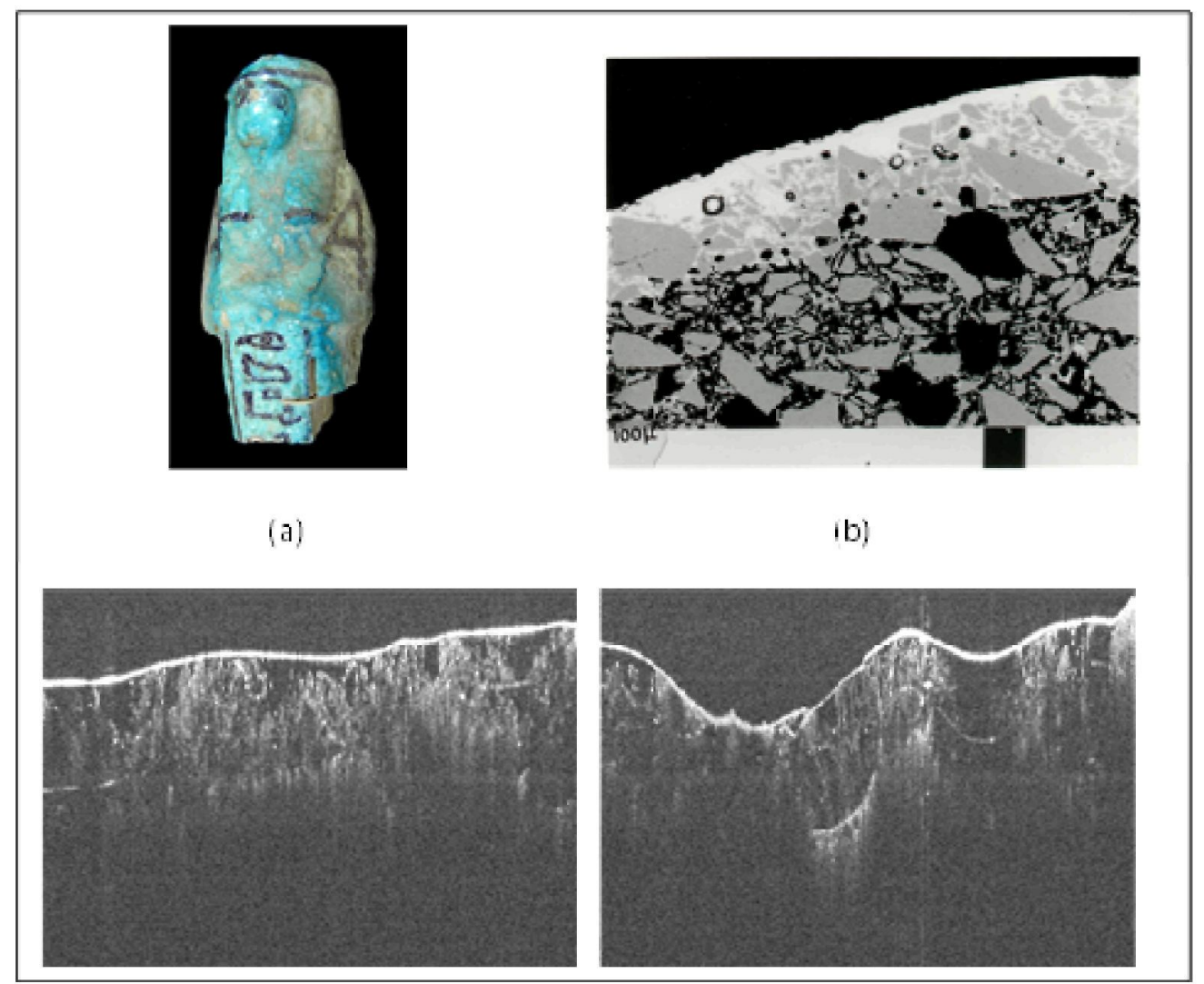

Figure 4: A fragmentary Egyptian Shabti of the 21st dynasty (BMRL16323): a) colour image of the object; b) SEM image of a polished section where the glaze layer appears white, the quartz grey and the resin-impregnated voids black. The black maker on the bottom left shows a scale of $400 \mu \mathrm{m}$.; c-d) OCT virtual cross-section images and a video. The OCT images are of the same scale and the white scale bars on the bottom left in (c) show scales of $400 \mu \mathrm{m}$. 


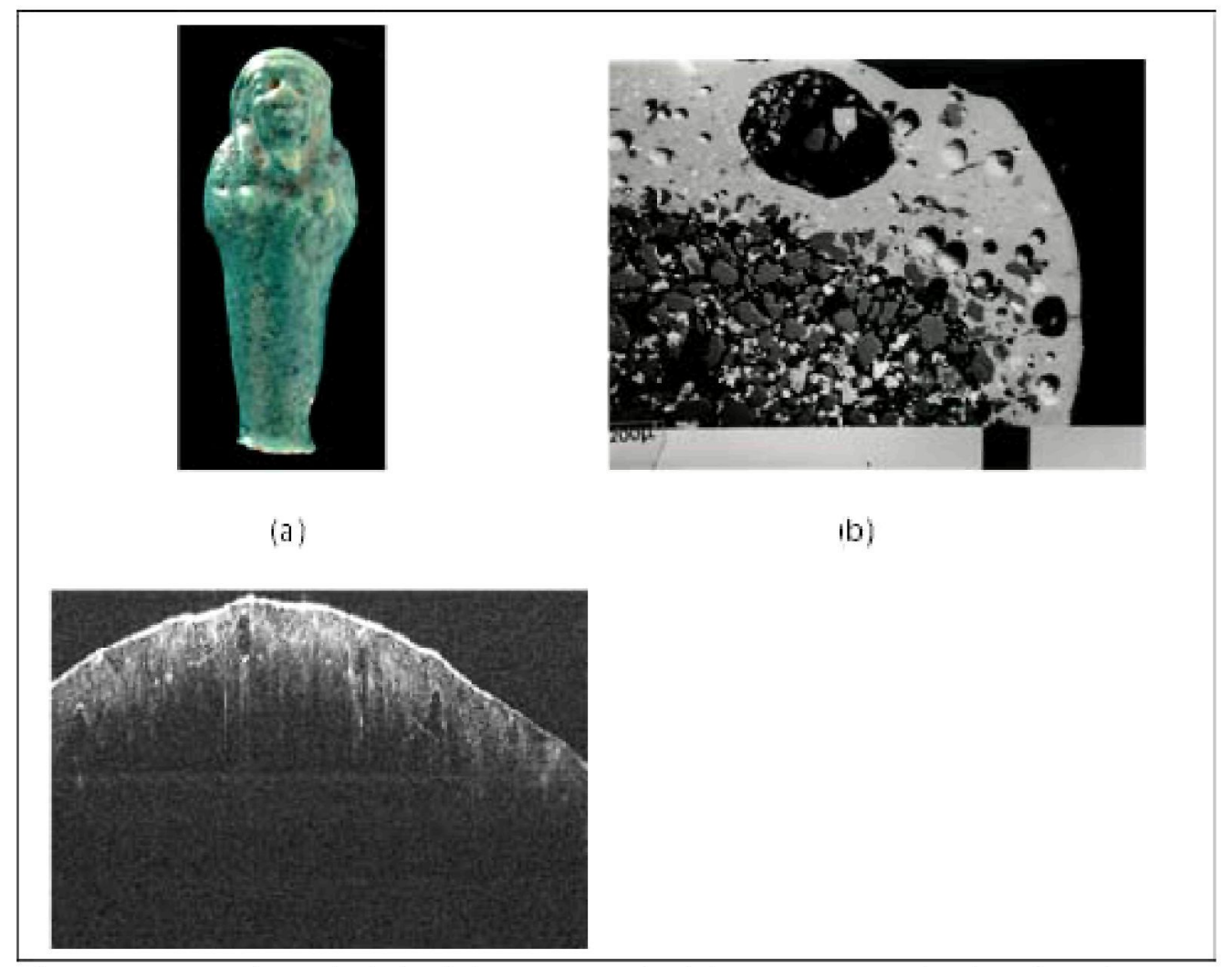

Figure 5: Egyptian Shabti of the Late Period (BMRL 16322): a) colour image of the object; b) SEM image of a polished section where the glaze appears light grey, the quartz particles dark grey and the voids black. The black marker on the bottom left of the image shows a scale of $400 \mu \mathrm{m}$; c) an OCT virtual cross-section image. The OCT images are of the same scale and the white scale bars on the bottom left in (c) show scales of $400 \mu \mathrm{m}$.

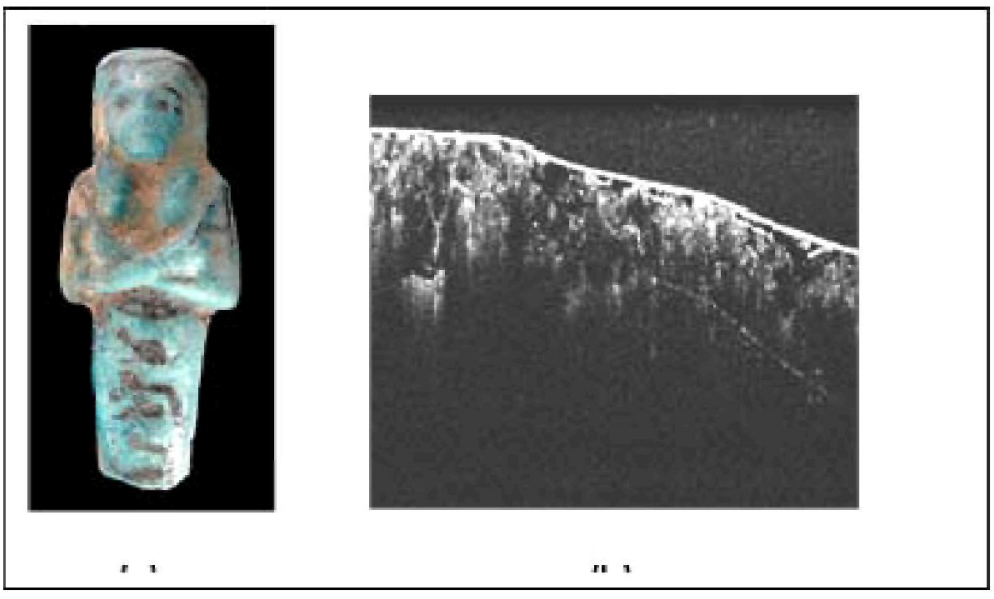

Figure 6. A fragmentary Egyptian Shabti of the $21^{\text {st }}$ dynasty (BMRL16324): a) colour image of the shabti; b) OCT virtual cross-section images. The white scale bars on the bottom left show scales of $400 \mu \mathrm{m}$. 


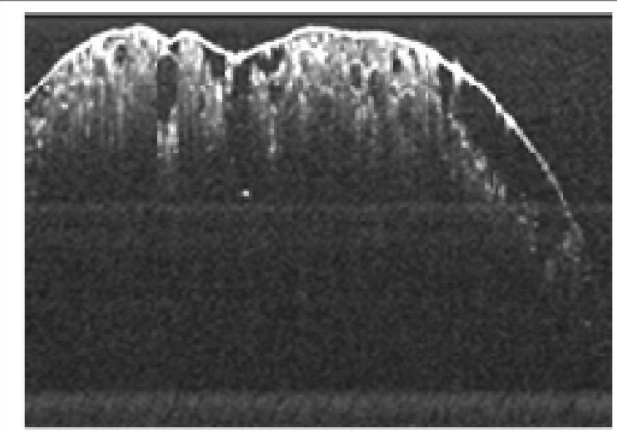

(a)

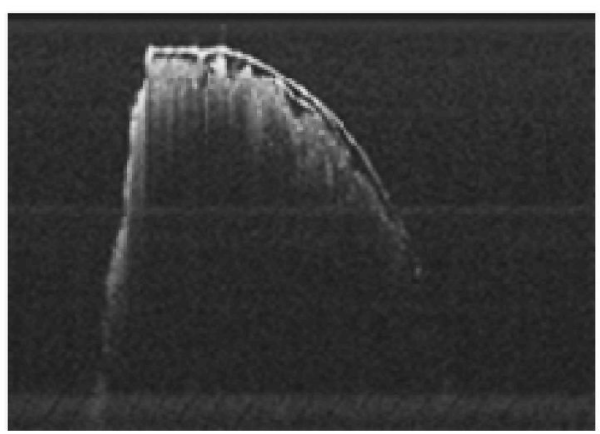

(c)

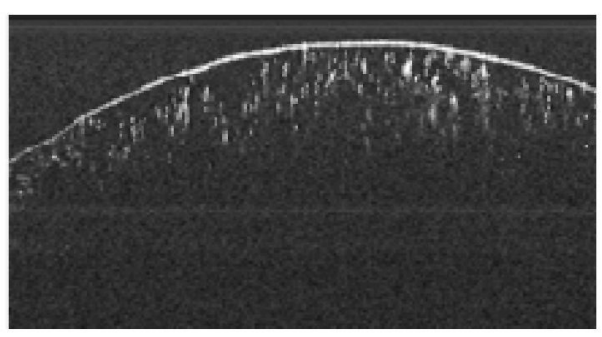

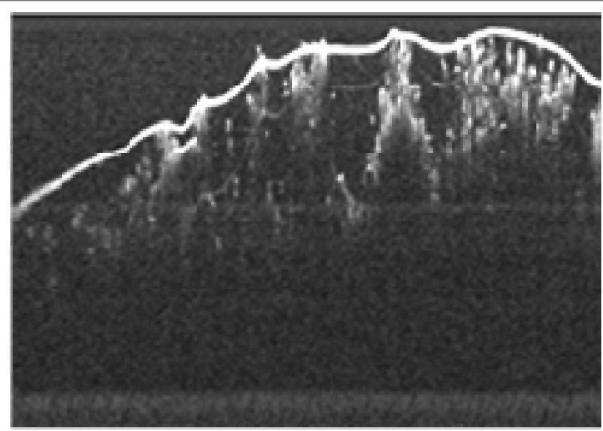

(b)

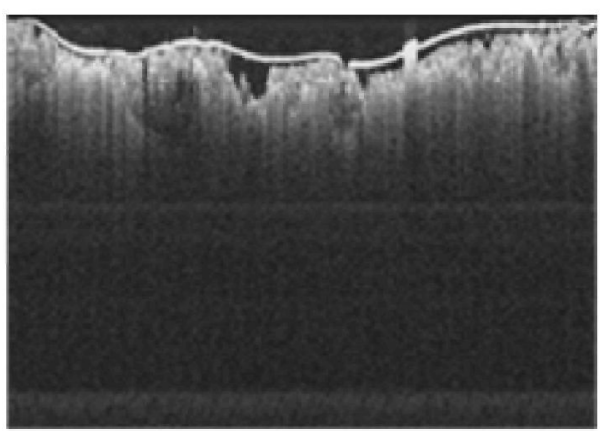

(d)

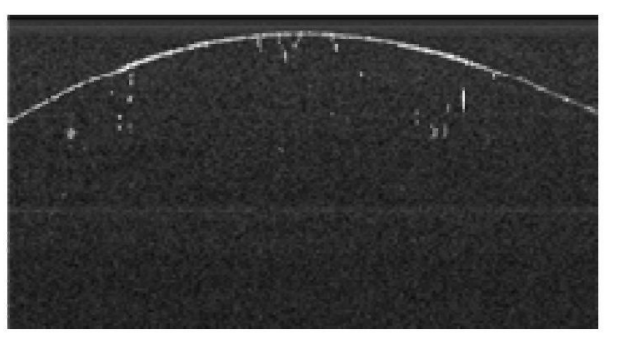

Figure 7: OCT images of laboratory manufactured beads using (a) and (b) efflorescence glazing method (beads fired at $850^{\circ} \mathrm{C}$ and $980^{\circ} \mathrm{C}$ respectively); (c) and (d) cementation (Qom) glazing method (front and underside of bead respectively); (e) and (f) direct application of fritted glazing mixture (beads fired at $850^{\circ} \mathrm{C}$ and $980^{\circ} \mathrm{C}$ respectively). The OCT images are of the same scale and the white scale bars on the bottom left in (a) show scales of $400 \mu \mathrm{m}$. 